\title{
Behavioral Effects of Psychomotor Stimulant Infusions into Amygdaloid Nuclei
}

\author{
Laura E. O'Dell, Ph.D., Amy N. Sussman, B.S., Kym L. Meyer, B.S., \\ and Janet L. Neisewander, Ph.D.
}

The role of amygdaloid nuclei in locomotion, stereotypy, and conditioned place preference (CPP) produced by psychomotor stimulants was examined. Five 2-day conditioning trials were conducted over 10 consecutive days. Rats received bilateral intracranial infusions of saline, cocaine (25-100 $\mu \mathrm{g} / \mathrm{side})$, or amphetamine (0.31-20 $\mu \mathrm{g} /$ side) into the ventricles (ICV), basolateral amygdala (BlA), or central amygdala (CeA) and were confined to a compartment. On alternating days, rats received sham infusions and were confined to a different compartment. Locomotion was measured daily, stereotypy was measured on trials 1 and 5, and CPP was measured $24 \mathrm{~h}$ after conditioning. ICV infusions of cocaine or amphetamine produced locomotion, rearing, and CPP. Intra-BlA and intra-CeA infusions of the highest dose of cocaine produced locomotion. In contrast, intra-CeA infusions of amphetamine potently produced locomotion and CPP. Intra-BlA infusions of amphetamine, however, did not produce any behavioral changes. These results suggest that the $\mathrm{CeA}$, but not the $\mathrm{BlA}$, is involved in initiating reward and locomotion produced by amphetamine.

[Neuropsychopharmacology 20:591-602, 1999] (C) 1999 American College of Neuropsychopharmacology. Published by Elsevier Science Inc.
KEY WORDS: Amphetamine; Cocaine; Conditioned place preference; Locomotion; Stereotypy; Drug-seeking behavior; Conditioning

The amygdala is a collection of anatomically and functionally diverse nuclei. The basolateral amygdala (BlA) is a cortical-like nucleus that plays an important role in forming associations between affective states and environmental stimuli, such as stimulus-reward associations (Alheid et al. 1992; Everitt and Robbins 1992). The central amygdala (CeA) is part of the extended amygdala, which is a collection of anatomically and developmentally related brain regions (see Alheid and Heimer 1988). The CeA plays a role in arousal, expression of emotions, and forming associations between environ-

From the Department of Psychology, Arizona State University, Tempe, Arizona.

Address correspondence to: Janet Neisewander, Ph.D., Department of Psychology, Arizona State University, Box 871104, Tempe, AZ 85287-1104.

Received April 15, 1998; revised July 13, 1998; accepted August 3, 1998 mental stimuli and affective states typically involving autonomic responses (see Kaada 1972; Kapp et al. 1992).

Considering the anatomy and functions of the BlA and the CeA, it seems likely that these nuclei play a role in the stimulant and rewarding properties of psychomotor stimulants. For example, both of these nuclei are connected anatomically with the nucleus accumbens (NAc), a structure that plays an important role in motor behaviors and reward produced by psychomotor stimulants (Carr and White 1986; Carr and White 1987; Delfs et al. 1990). Specifically, the BlA sends dense excitatory projections to the NAc, and both the CeA and the NAc are part of the extended amygdala (Fuller et al. 1987; McDonald 1996). In addition, the CeA receives dense dopamine (DA) efferents from the ventral tegmental area, and consequently, has more DA terminals relative to other amygdaloid nuclei (Ben-Ari et al. 1975; Kilts and Anderson 1987; Ungerstedt 1971). The CeA also projects back to the ventral tegmental area and substantia nigra compacta, which contain the cell bodies of the mesocorticolimbic and nigrostriatal DA systems, respectively (Wallace et al. 1992). These reciprocal connec- 
tions suggest that the CeA likely influences the mesocorticolimbic and nigrostriatal DA systems that mediate motor behaviors and reward produced by psychomotor stimulants (for a recent review see Koob et al. 1993). The role of the $\mathrm{BlA}$ and the $\mathrm{CeA}$ in forming associations between affective states and environmental stimuli is also relevant to reward produced by psychomotor stimulants, as drug-associated stimuli can enhance motor behaviors produced by psychomotor stimulants and reinstate drug-seeking behavior (Gerber and Strech 1975; Post et al. 1987; Stewart 1992). Furthermore, the role of the CeA in arousal and the expression of emotions may be related to drug abuse processes.

Studies comparing the role of the BlA and the CeA in reward have demonstrated that these nuclei may be differentially involved in reward-related processes. The BlA plays an important role in forming stimulus-reward associations. For example, lesions of the BlA disrupt operant responding for a stimulus paired previously with food (Hatfield et al. 1996; Robledo et al. 1996), sucrose (Burns et al. 1993), water (Cador et al. 1989), or a receptive female (Everitt et al. 1989). In addition, lesions of the BlA abolish the ability of drug-associated cues to reinstate cocaine self-administration (SA) behavior (Meil and See 1997). In contrast, previous studies suggest that the CeA plays a role in processing the reward value associated with a stimulus. For example, lesions of the CeA disrupt the ability of animals to adjust conditioned responding following postconditioning changes in the value of the primary reinforcer (Hatfield et al. 1996) and disrupt memory for the magnitude of reinforcement on an 8-arm radial maze (Kesner et al. 1989). Lesions of the $\mathrm{CeA}$ also disrupt the ability of intra-NAc infusions of amphetamine to potentiate conditioned reinforcement (Robledo et al. 1996). Furthermore, the CeA may play a direct role in reward-related processes, as stimulation of the $\mathrm{CeA}$, but not the BlA, supports electrical brain self-stimulation (Wurtz and Olds 1963). Collectively, these studies suggest that the BlA is important for forming stimulus-reward associations, whereas the CeA is important for processing reward value.

Previous research suggests that the $\mathrm{BlA}$ and the CeA play a role in reward produced by psychomotor stimulants. For example, SA studies suggest that the BlA and the CeA play a role in reward produced by cocaine, as both lesions and intra-BlA or intra-CeA administration of the DA D1 antagonist SCH 23390 decrease cocaine SA behavior, consistent with reward reduction (Caine et al. 1995; McGregor and Roberts 1993; McGregor et al. 1994; Whitelaw et al. 1996). However, Deminere et al. (1988) demonstrated that 6-hydroxydopamine (6-OHDA) lesions of the BlA shift the amphetamine SA doseresponse curve to the left, consistent with reward enhancement. The discrepancy between these studies may be due to the different effects of cocaine and amphetamine, or the manipulation used to alter DA neurotrans- mission. For example, 6-OHDA lesions of the amygdala also produce an increase in DA turnover in the NAc (Deminere et al. 1988). Therefore, the facilitation of amphetamine reward following 6-OHDA lesions may be due to increased DA neurotransmission in the NAc. Collectively, the SA studies suggest that the BlA and the CeA play a role in the reward produced by psychomotor stimulants.

Conditioned place preference (CPP) studies also suggest that the amygdala plays a role in reward produced by psychomotor stimulants, as lesions of the entire amygdala disrupt cocaine-CPP (Brown and Fibiger 1993). However, the lateral portions of the amygdala appear to mediate amphetamine-CPP, as this effect is disrupted by lesions of the lateral amygdala but not by lesions of the BlA or CeA (Hiroi and White 1991). This study suggests that neither the $\mathrm{BlA}$ or the $\mathrm{CeA}$ are necessary for amphetamine reward. However, it is presently unclear whether stimulation of these nuclei is sufficient to produce CPP. One study that addressed this question demonstrated that intra-CeA infusions of amphetamine do not produce CPP (Carr and White 1986). The focus of that study, however, was to compare the effects of amphetamine infusions into several brain regions using a single dose of amphetamine that produced CPP following intra-NAc administration. Therefore, it is possible that intra-amygdaloid infusions of another dose of amphetamine or cocaine would produce CPP.

It is also unclear whether the BlA or CeA plays a role in stimulant behavior produced by cocaine and amphetamine. For example, Carr and White (1987) demonstrated that bilateral infusions of amphetamine into the CeA produces an increase in standing still and no changes in any component of stereotypy. The results from the Carr and White study do not preclude the role of the CeA in initiating motor behaviors because only one dose of amphetamine was injected into the CeA. Furthermore, it is possible that other amygdaloid nuclei may play a role in initiating these behaviors. Indeed, Wang and Rebec (1996) demonstrated that unilateral infusions of amphetamine into the amygdala, but not directed at a specific nucleus, elicit rotational behavior, rearing, and sniffing.

The present study assessed whether the CeA and/or the $\mathrm{BlA}$ are involved in initiating the rewarding and stimulant effects produced by psychomotor stimulants. This question was examined by investigating whether infusions of various doses of cocaine or amphetamine into the $\mathrm{CeA}$ or the BlA would produce $\mathrm{CPP}$, locomotion, and/or stereotypy.

\section{MATERIALS AND METHODS}

\section{Animals}

Male Sprague-Dawley rats weighing $325 \pm 25$ g were housed individually in a climate controlled facility with 


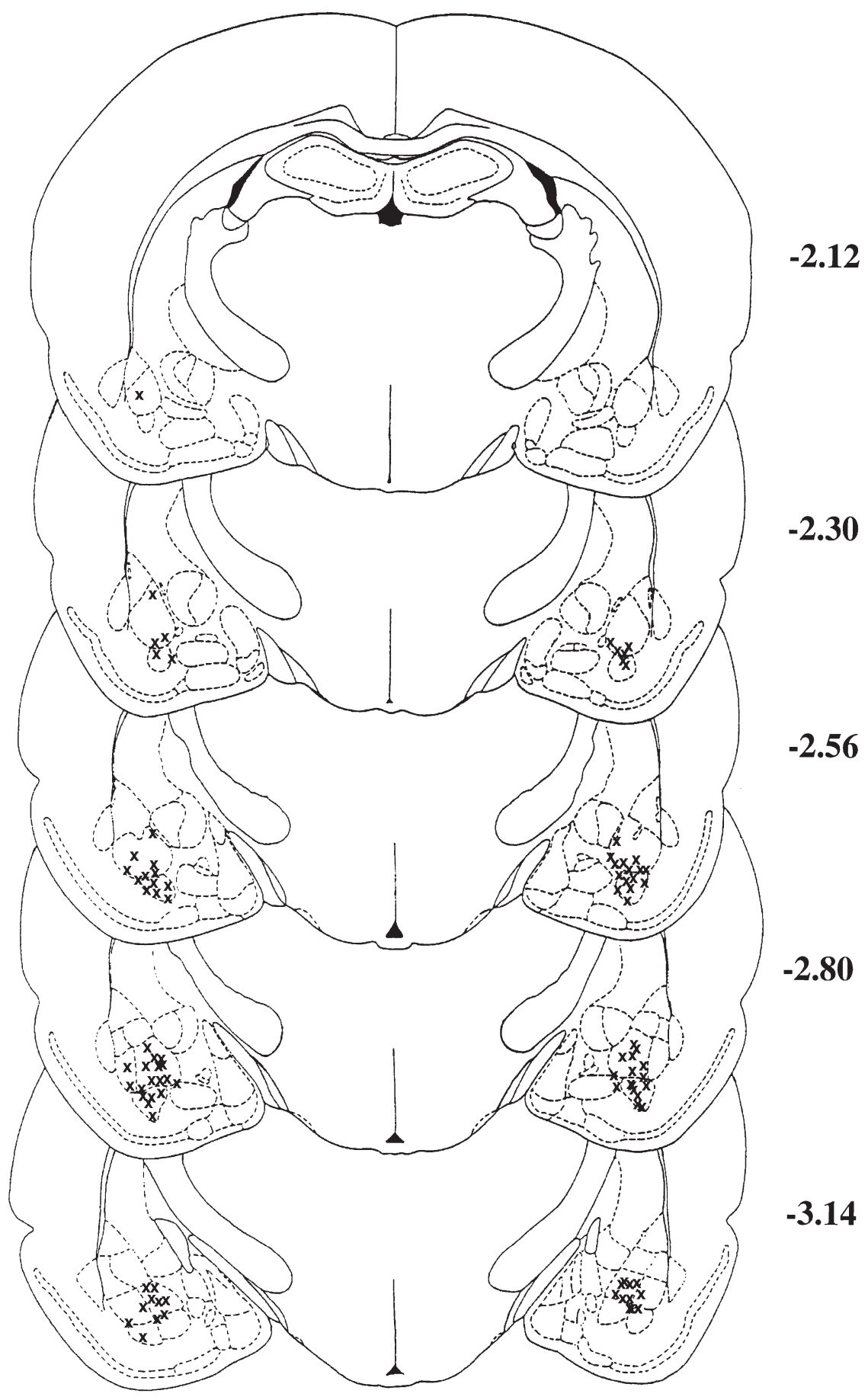

Figure 1. Approximate placements of injection cannulae within the basolateral amygdala. The Xs represent the most ventral point of the tract estimated during tissue sectioning. Drawings were adapted from the Paxinos and Watson (1986) atlas.

a 12-h light/dark cycle. They were acclimated to handling for $4-5$ days before surgery.

\section{Surgical Procedure}

Rats were anesthetized using sodium pentobarbital (50 $\mathrm{mg} / \mathrm{kg}$, IP) in conjunction with atropine sulfate $(10 \mathrm{mg} /$ $\mathrm{kg}$, IP). Their heads were then shaved and cleaned, and they were placed into a stereotaxic instrument. A midsagi- tal incision was made across the skull, and the connective tissue was retracted. Guide cannulae (23 gauge stainless steel) were implanted bilaterally into either the lateral ventricles, the $\mathrm{BlA}$, or the CeA using the following coordinates, respectively: $-0.9 \mathrm{~mm} \mathrm{AP}$ and $\pm 1.4 \mathrm{~mm} \mathrm{ML}$ with respect to bregma, and $-2.7 \mathrm{~mm}$ DV from the surface of the skull; $-2.6 \mathrm{~mm} \mathrm{AP}$ and $\pm 4.8 \mathrm{~mm}$ ML with respect to bregma, and $-7.6 \mathrm{~mm}$ DV from the surface of the skull; $-2.6 \mathrm{~mm} \mathrm{AP}$ and $\pm 4.3 \mathrm{~mm} \mathrm{ML}$ with respect to bregma, 


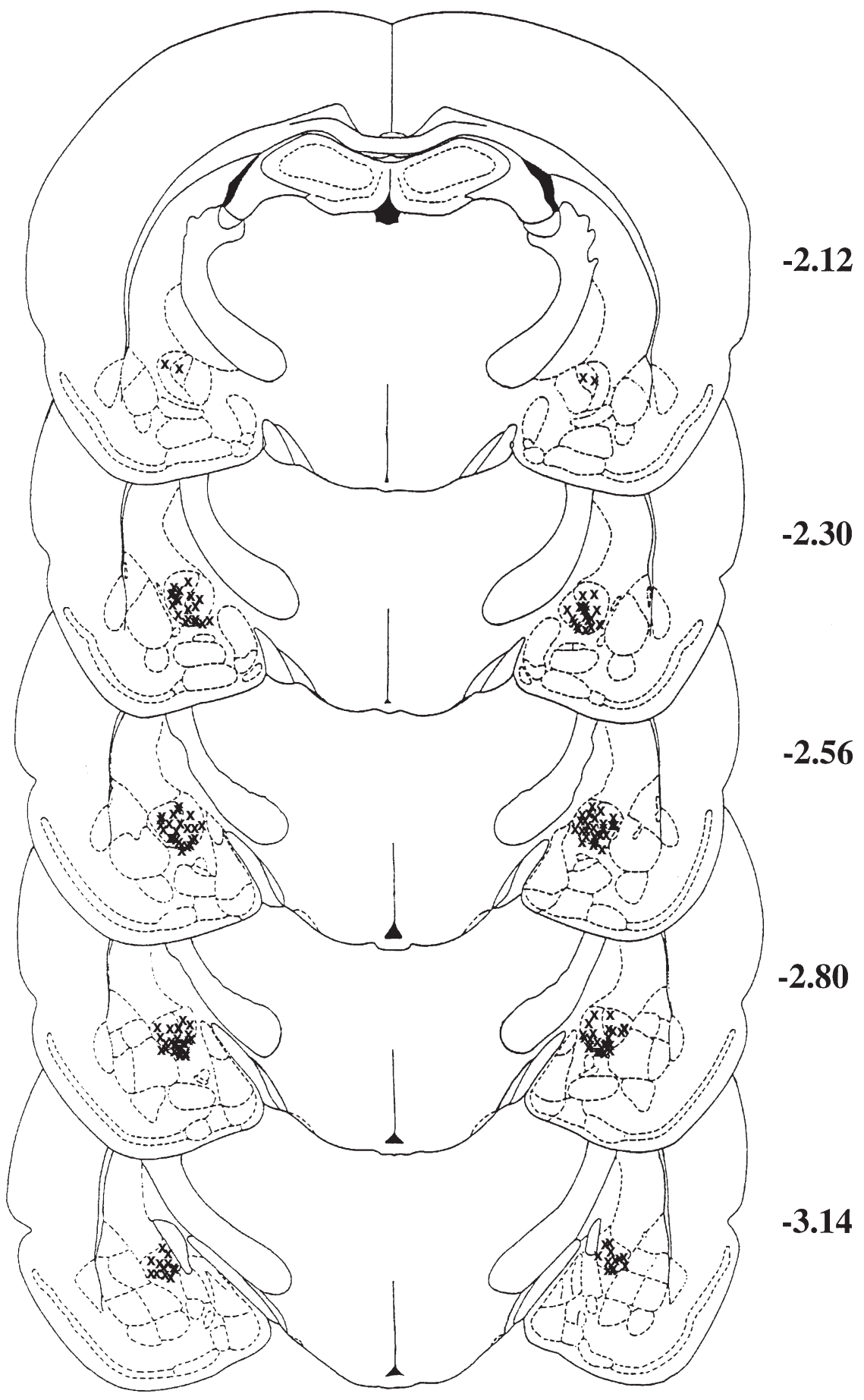

Figure 2. Approximate placements of injection cannulae within the central amygdala. The Xs represent the most ventral point of the tract estimated during tissue sectioning. Drawings were adapted from the Paxinos and Watson (1986) atlas.

and $-7.1 \mathrm{~mm}$ DV from the surface of the skull. The coordinates were derived using the Paxinos and Watson (1986) atlas. Three small screws were placed around the cannulae, and the screws and cannulae were secured to the skull using dental acrylic cement. Approximately $12 \mathrm{~h}$ after surgery, wire stylets were placed into the guide cannulae to maintain patency. The rats were allowed 4 days to recover from surgery and were handled each recovery day.

\section{Apparatus}

Behavioral testing was conducted in rectangular Plexiglas chambers $76 \times 24 \times 30 \mathrm{~cm}$ high. Each chamber consisted of two compartments separated by a removable partition that bisected the chamber. One compartment had pine scented bedding beneath a wire mesh floor and all but the front wall were white. The other compartment had cedar scented bedding beneath a bar 


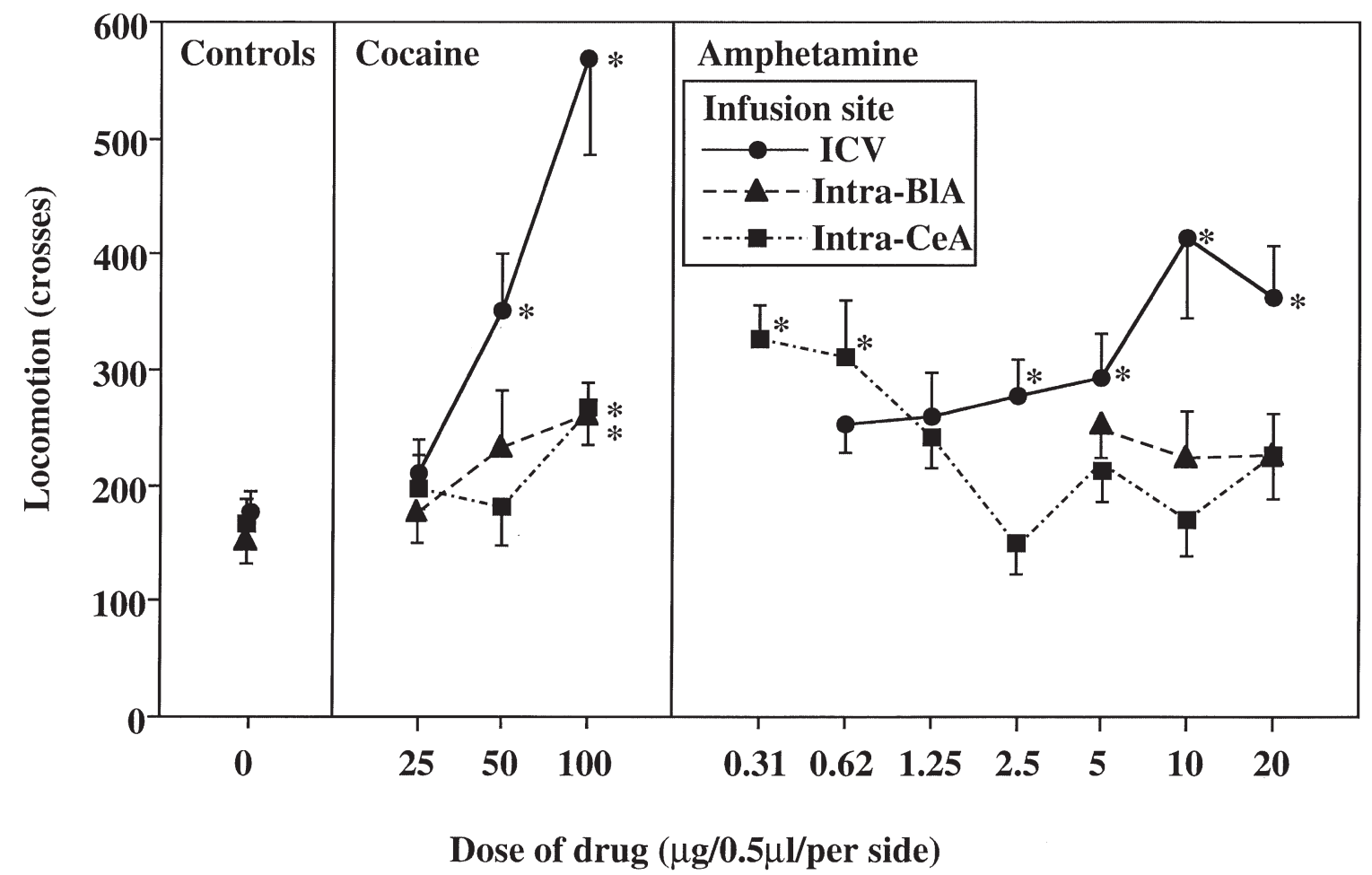

Figure 3. Locomotion (crosses \pm SEM) totaled across trials following ICV (circles), intra-BlA (triangles), or intra-CeA (squares) administration of saline, cocaine, or amphetamine. Asterisks represent a significant difference from saline controls (Fisher LSD test, $p<.05$ ).

grid floor and all but the front wall were black. The front wall of the chambers was transparent to allow direct observation of the rats' behavior. On the CPP test days, the solid partition was replaced by a similar partition that contained an opening in the center $(8 \times 8 \mathrm{~cm}$ high) that allowed the rats free access to both compartments simultaneously. Preliminary experiments demonstrated that rats exhibit equal preference for the two compartments (O'Dell et al. 1996). Each compartment had two sets of photocells and detectors mounted opposite each other $27 \mathrm{~cm}$ apart and $4 \mathrm{~cm}$ above the floor. A computer-automated relay system recorded the number of times the individual photobeams were interrupted consecutively by the rat crossing from one end of the compartment to the other (i.e., crosses).

\section{Experimental Design and Conditioning Procedure}

Rats were randomly assigned to receive ICV, intra-BlA, or intra-CeA infusions of saline $(N=12-15), d$-amphetamine $(0.31,0.62,1.25,5,10$, or $20 \mu \mathrm{g} / 0.5 \mu \mathrm{l} ; N=7-10$ per dose), or cocaine $(25,50$, or $100 \mu \mathrm{g} / 0.5 \mu \mathrm{l} ; N=7-12$ per dose). To administer an intracranial infusion, the injection cannulae (30 gauge stainless steel) were connected via PE20 tubing to $10 \mu$ l Hamilton syringes placed in an infusion pump. They were inserted to a depth $1 \mathrm{~mm}$ beyond the guide cannulae. One minute later, the pump was activated and administered $0.5 \mu l$ over $3 \mathrm{~min}$ and $10 \mathrm{~s}$. The injection cannulae were left in place for $1 \mathrm{~min}$ following the infusion. Sham infusions were administered in the same manner, except no fluid was infused.

Each conditioning trial took place over a 2-day period. On one day, rats received bilateral infusions of saline or their assigned dose of cocaine or amphetamine and were immediately placed into their infusion-paired compartment for $30 \mathrm{~min}$. The following day, the rats received bilateral sham infusions and were immediately placed into the sham-paired compartment for $30 \mathrm{~min}$. The sham infusion procedure was used in order to minimize tissue damage from repeated intracranial infusions. This 2-day conditioning procedure was repeated over 10 consecutive days for a total of 5 conditioning trials. The particular compartment paired with the infusion and the order of placement into the infusion-paired versus sham-paired compartments were counterbalanced across groups.

\section{Behavioral Testing}

Locomotion was recorded daily by the computer-automated system. Stereotypic behaviors including rearing, sniffing, and headbobbing were recorded following the first and last intracranial infusion every $10 \mathrm{~s}$ for the duration of the 30-min test period. These measures were recorded by an observer who was unaware of the rats' previous treatment. 
Table 1. Stereotypic Behaviors Following Intracranial Administration of Cocaine or Amphetamine.

\begin{tabular}{|c|c|c|c|c|}
\hline \multirow[b]{2}{*}{ Route of Administration } & \multirow{2}{*}{$\begin{array}{c}\text { Dose of Drug } \\
(\mu \mathrm{g} / 0.5 \mu \mathrm{l})\end{array}$} & \multicolumn{3}{|c|}{ Time-Sampled Behaviors ${ }^{a}$} \\
\hline & & Sniffing & Rearing & Headbobbing \\
\hline \multicolumn{5}{|l|}{ Ventricles } \\
\hline Saline & 0 & $108.6 \pm 10.4$ & $18.4 \pm 2.3$ & $0.33 \pm .21$ \\
\hline \multirow[t]{3}{*}{ Cocaine } & 25 & $107.7 \pm 19.7$ & $21.1 \pm 6.6$ & $0.71 \pm 0.30$ \\
\hline & 50 & $139.8 \pm 12.9$ & $36.8 \pm 6.3^{*}$ & $0.71 \pm 0.42$ \\
\hline & 100 & $147.6 \pm 20.3$ & $39.7 \pm 8.9^{*}$ & $0.55 \pm 0.37$ \\
\hline \multirow[t]{6}{*}{ Amphetamine } & 0.62 & $90.3 \pm 7.6$ & $31.4 \pm 5.6^{*}$ & $0 \pm 0$ \\
\hline & 1.25 & $102.1 \pm 20.2$ & $30.5 \pm 5.5^{*}$ & $0 \pm 0$ \\
\hline & 2.5 & $84.3 \pm 8.1$ & $29.5 \pm 4.3^{*}$ & $0 \pm 0$ \\
\hline & 5 & $85.8 \pm 6.7$ & $31.2 \pm 5.0^{*}$ & $0.43 \pm 0.20$ \\
\hline & 10 & $113.6 \pm 5.3$ & $34.5 \pm 4.0^{*}$ & $0.22 \pm 0.22$ \\
\hline & 20 & $116.1 \pm 10.1$ & $33.8 \pm 5.5^{*}$ & $0.25 \pm 0.25$ \\
\hline \multicolumn{5}{|l|}{ Basolateral amygdala } \\
\hline Saline & 0 & $110.5 \pm 12.9$ & $24.0 \pm 7.3$ & $0.91 \pm 0.48$ \\
\hline \multirow[t]{3}{*}{ Cocaine } & 25 & $117.2 \pm 20.8$ & $21.3 \pm 4.8$ & $1.0 \pm 0.59$ \\
\hline & 50 & $126.6 \pm 17.8$ & $27.6 \pm 9.3$ & $1.1 \pm 0.67$ \\
\hline & 100 & $154.5 \pm 8.6$ & $25.8 \pm 3.5$ & $1.1 \pm 0.38$ \\
\hline \multirow[t]{3}{*}{ Amphetamine } & 5 & $102.4 \pm 6.0$ & $18.2 \pm 3.0$ & $0.22 \pm 0.22$ \\
\hline & 10 & $68.5 \pm 9.8$ & $21.0 \pm 3.6$ & $0.28 \pm 0.28$ \\
\hline & 20 & $93.1 \pm 10.2$ & $27.3 \pm 6.4$ & $0 \pm 0$ \\
\hline \multicolumn{5}{|l|}{ Central amygdala } \\
\hline Saline & 0 & $87.1 \pm 10.9$ & $23.4 \pm 4.3$ & $0.08 \pm 0.08$ \\
\hline \multirow[t]{3}{*}{ Cocaine } & 25 & $67.2 \pm 10.4$ & $23.2 \pm 5.5$ & $0 \pm 0$ \\
\hline & 50 & $69.8 \pm 8.4$ & $29.7 \pm 7.1$ & $0.12 \pm 0.12$ \\
\hline & 100 & $103.1 \pm 13.2$ & $24.0 \pm 2.8$ & $0.07 \pm 0.07$ \\
\hline \multirow[t]{7}{*}{ Amphetamine } & 0.31 & $84.1 \pm 6.6$ & $46.7 \pm 3.1^{*}$ & $0 \pm 0$ \\
\hline & 0.62 & $86.5 \pm 9.7$ & $29.2 \pm 4.0$ & $0.25 \pm 0.25$ \\
\hline & 1.25 & $79.6 \pm 15.4$ & $29.0 \pm 2.9$ & $0 \pm 0$ \\
\hline & 2.5 & $78.6 \pm 12.2$ & $24.1 \pm 4.9$ & $0 \pm 0$ \\
\hline & 5 & $87.8 \pm 15.6$ & $20.4 \pm 3.8$ & $0 \pm 0$ \\
\hline & 10 & $60.0 \pm 4.8$ & $17.5 \pm 4.2$ & $0 \pm 0$ \\
\hline & 20 & $85.1 \pm 7.5$ & $23.7 \pm 3.5$ & $0 \pm 0$ \\
\hline
\end{tabular}

The day after the conditioning procedure was completed, the rats were tested for CPP. The solid partition was removed and replaced with a partition that contained an opening, allowing the rats free access to both compartments simultaneously. All rats were placed into the black compartment initially such that, within each experimental condition, half of the rats were placed into their infusion-paired compartment and the other half were placed into their sham-paired compartment. The amount of time the rats spent in each compartment was then measured for $15 \mathrm{~min}$ by an observer who was unaware of the rats' previous treatment. Entry into a compartment was defined as both of the rats' front paws contacting the floor of that compartment.

\section{Verification of Cannulae Placements}

Rats received a $0.5-\mu \mathrm{l} /$ side infusion of black ink (Carter's, Neat-Flo). Approximately 5-10 min after the infusion, the rats were decapitated, and their brains were removed. Cannulae placements for each subject were estimated as the most ventral point of the tract using the Paxinos and Watson (1986) atlas. Cannula placements into the ventricles were evident from the spread of black ink throughout the lateral ventricles.

\section{Statistical Analyses}

Motor behaviors were analyzed using one-way ANOVAs totaled across all trials for locomotion and trials 1 and 5 for stereotypic behaviors. Subsequent pairwise comparisons were made using Fisher LSD tests. CPP data were analyzed using one-way ANOVAs to compare time spent in the infusion-paired compartment across treatment groups. Subsequent pairwise comparisons were made using Fisher LSD tests to compare time spent in the infusion-paired compartment in drugtreated rats relative to their respective saline controls. 


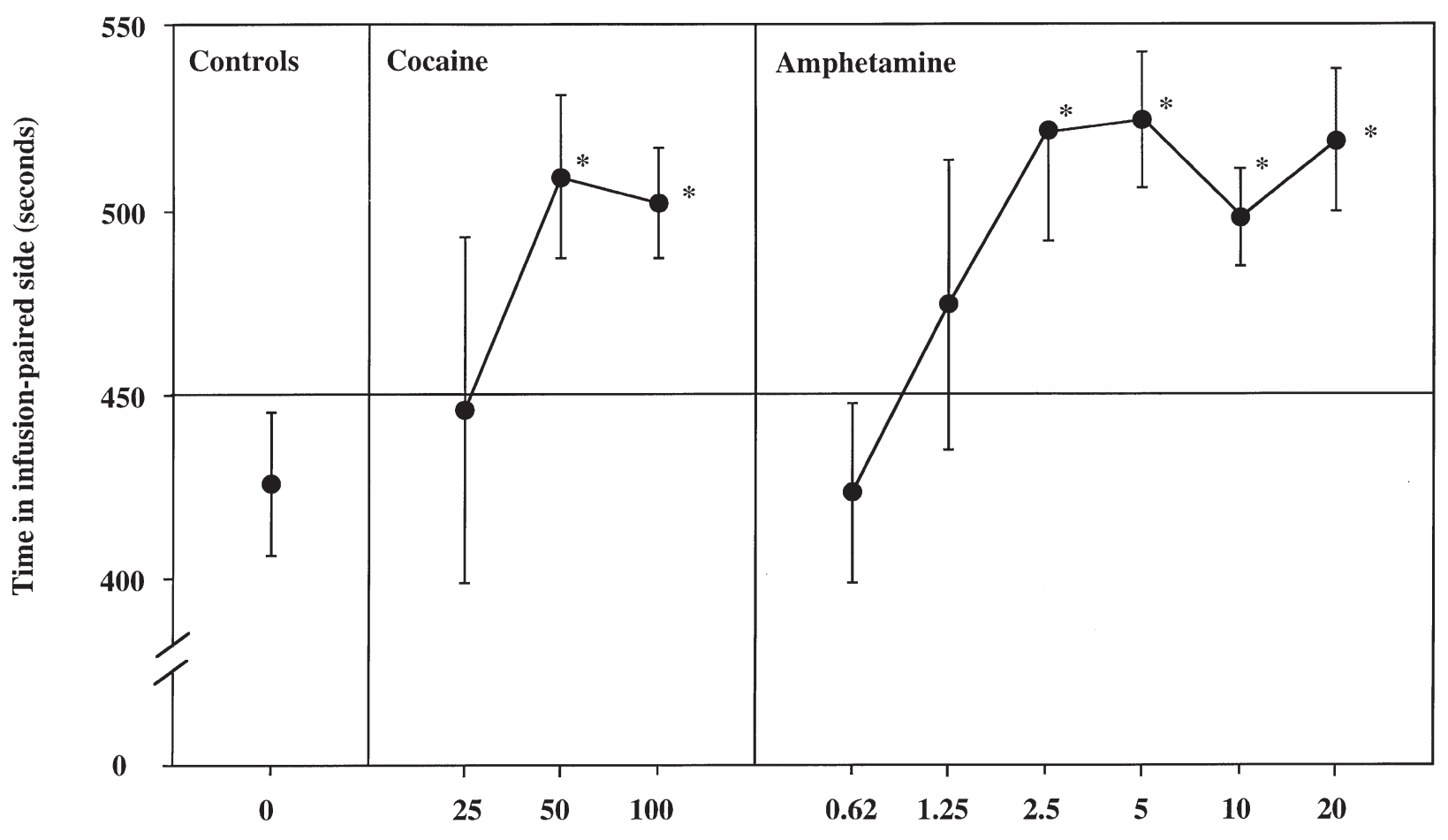

Dose of drug $(\mu \mathrm{g} / 0.5 \mu \mathrm{l} /$ per side $)$

Figure 4. Time spent (sec \pm SEM) in the infusion-paired compartment in rats that previously received ICV infusions of saline, cocaine, or amphetamine. The horizontal line represents $50 \%$ of the total test time, such that values above the line reflect a preference for the infusion-paired compartment. Asterisks represent a significant increase in the amount of time spent in the infusion-paired side in conditioned rats relative to saline controls (Fisher LSD test, $p<.05$ ).

\section{RESULTS}

\section{Cannula Placements}

Figure 1 illustrates the approximate point of drug infusion into the BlA, and Figure 2 illustrates the approximate point of drug infusion in the CeA. All cannula placements were located within $0.6 \mathrm{~mm}$ of the intended site of infusion.

\section{Locomotion}

Figure 3 illustrates dose-dependent effects of ICV, intra$\mathrm{BlA}$, or intra-CeA infusions of cocaine or amphetamine on locomotion totaled across trials. As expected, ICV infusions of cocaine produced an increase in locomotion $(\mathrm{F}[3,34]=15.2, p<.0001)$. Rats receiving 50 or $100 \mu \mathrm{g} /$ side of cocaine exhibited an increase in locomotion relative to saline controls ( $p<.05$, Fisher LSD test). In contrast, both intra-BlA and intra-CeA infusions of cocaine produced only a slight increase in locomotion $(\mathrm{F}[3,34]=$ $3.2, p<.03 ; \mathrm{F}[3,35]=3.0, p<.04$, respectively). Rats receiving $100 \mu \mathrm{g} /$ side of cocaine into either nucleus exhibited an increase in locomotion relative to saline controls ( $p<.05$, Fisher LSD test).
As expected, ICV infusions of amphetamine also produced an increase in locomotion $(\mathrm{F}[6,57]=4.85, p<$ $.001)$. Rats receiving $2.5-20 \mu \mathrm{g} /$ side of amphetamine exhibited an increase in locomotion relative to saline controls ( $p<.05$, Fisher LSD test). Intra-BlA infusions of amphetamine produced a trend toward an increase in locomotion $(\mathrm{F}[3,34]=2.7, p<.06)$. In fact, post-hoc comparisons revealed that rats receiving $5 \mu \mathrm{g} /$ side of amphetamine exhibited an increase in locomotion relative to saline controls $(p<.05$, Fisher LSD test). Intra$\mathrm{CeA}$ infusions of amphetamine produced a significant increase in locomotion $(\mathrm{F}[7,64]=4.4, p<.001)$. Rats receiving 0.31 or $0.62 \mu \mathrm{g} /$ side of amphetamine exhibited an increase in locomotion relative to saline controls $(p<$ .05 , Fisher LSD test).

\section{Stereotypic Behavior}

Table 1 illustrates dose-dependent effects of ICV, intra$\mathrm{BlA}$, and intra-CeA infusions of saline, cocaine, or amphetamine on stereotypic behavior totaled across trials 1 and 5. Rearing was the only stereotypic behavior that was altered by the infusions. Rearing dose-dependently increased following ICV infusions of cocaine $(F[3,34]=$ 


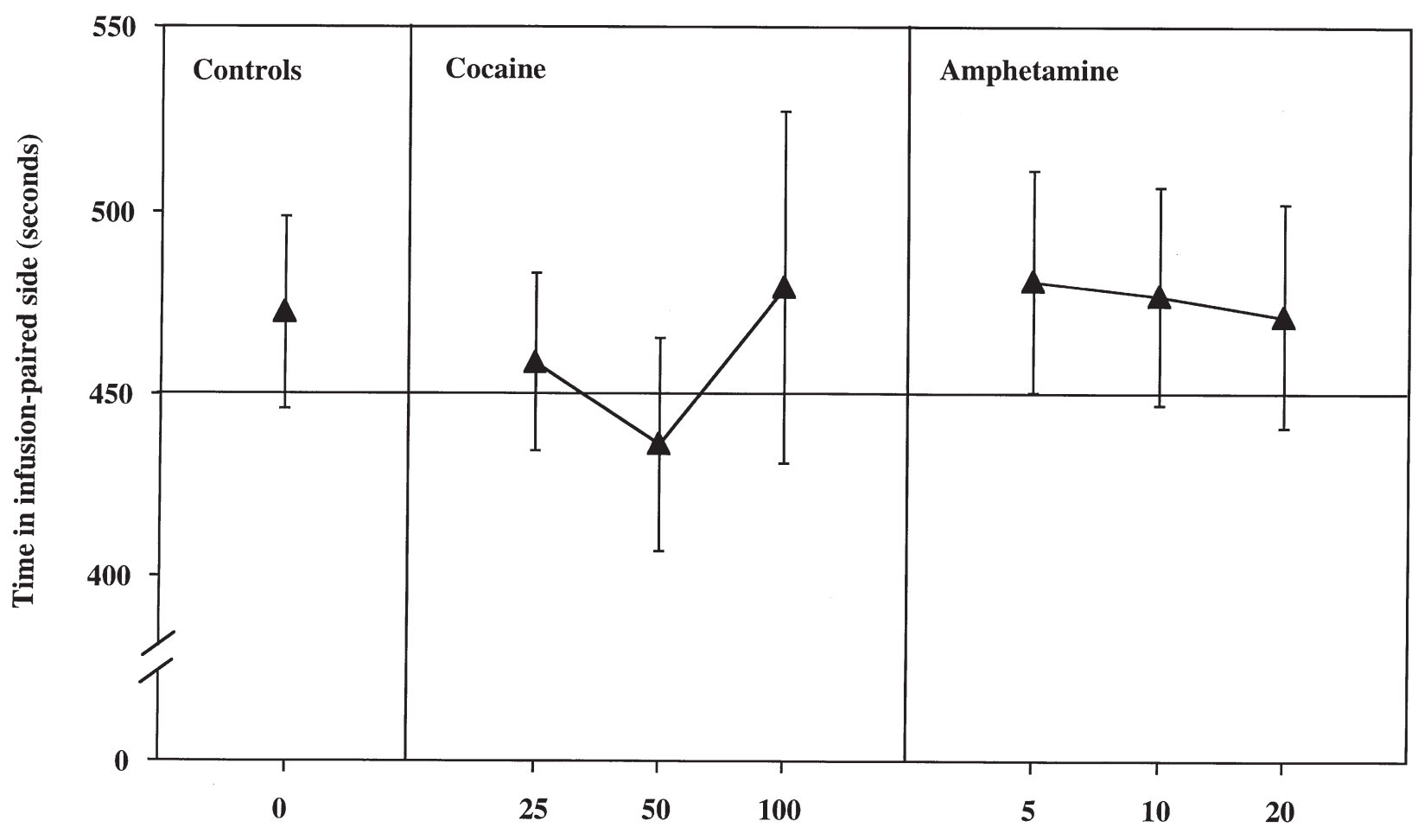

Dose of drug $(\mu \mathrm{g} / 0.5 \mu \mathrm{l} /$ per side $)$

Figure 5. Time spent (sec $\pm \mathrm{SEM}$ ) in the infusion-paired compartment in rats that previously received intra-BlA infusions of saline, cocaine, or amphetamine. The horizontal line represents $50 \%$ of the total test time, such that values above the line reflect a preference for the infusion-paired compartment.

$3.8, p<.01)$ or amphetamine $(\mathrm{F}[6,57]=2.2, p<0.05)$. Rats receiving 50 or $100 \mu \mathrm{g} /$ side of cocaine or $0.62-20$ $\mu \mathrm{g} /$ side of amphetamine exhibited an increase in rearing relative to saline controls ( $p<.05$, Fisher LSD test). In addition, rearing dose-dependently increased following intra-CeA infusions of amphetamine $(F[7,64]=$ $4.1, p<.001)$. Rats receiving $0.31 \mu \mathrm{g} /$ side of amphetamine exhibited an increase in rearing relative to saline controls $(p<.05$, Fisher LSD test).

\section{Conditioned Place Preference}

ICV infusions of either cocaine or amphetamine produced CPP. Figure 4 illustrates the amount of time animals spent in the infusion-paired compartment in rats that previously received ICV infusions of saline, cocaine, or amphetamine. The ANOVA revealed a main effect of dose in rats receiving ICV infusions of either cocaine $(\mathrm{F}[3,34]=2.8, p<.05)$ or amphetamine $(\mathrm{F}[6,57]=$ $3.4, p<.005)$. Rats receiving 50 or $100 \mu \mathrm{g} /$ side of cocaine or $2.5-20 \mu \mathrm{g} /$ side of amphetamine spent significantly more time in the infusion-paired compartment relative to saline controls ( $p<.05$, Fisher LSD test).

Intra-BlA infusions of either cocaine or amphetamine did not produce CPP. Figure 5 illustrates the amount of time animals spent in the infusion-paired compartment in rats that previously received intra-BlA infusions of saline, cocaine, or amphetamine. There was no significant main effect of dose in rats receiving intra-BlA infusions of either cocaine $(\mathrm{F}[3,34]=0.26, p<.85)$ or amphetamine $(\mathrm{F}[3,34]=0.02, p<.99)$.

Intra-CeA infusions of cocaine produced a trend toward CPP at the highest dose only, whereas intra-CeA infusions of amphetamine potently produced CPP. Figure 6 illustrates the amount of time animals spent in the infusion-paired compartment in rats that previously received intra-CeA infusions of saline, cocaine, or amphetamine. There was no significant main effect of dose in rats receiving intra-CeA infusions of cocaine $(\mathrm{F}[3,37]=$ $2.0, p<.12)$. However, rats receiving $100 \mu \mathrm{g} /$ side of cocaine exhibited a trend towards spending more time in the infusion-paired compartment relative to saline controls $(p<.05$, Fisher LSD test). There was a main effect of dose in rats receiving intra-CeA infusions of amphetamine $(F[7,64]=2.9, p<.01)$. Rats receiving 2.5 and 5 $\mu \mathrm{g} /$ side of amphetamine spent significantly more time in the infusion-paired compartment relative to saline controls ( $p<.05$, Fisher LSD test). In addition, rats receiv- 


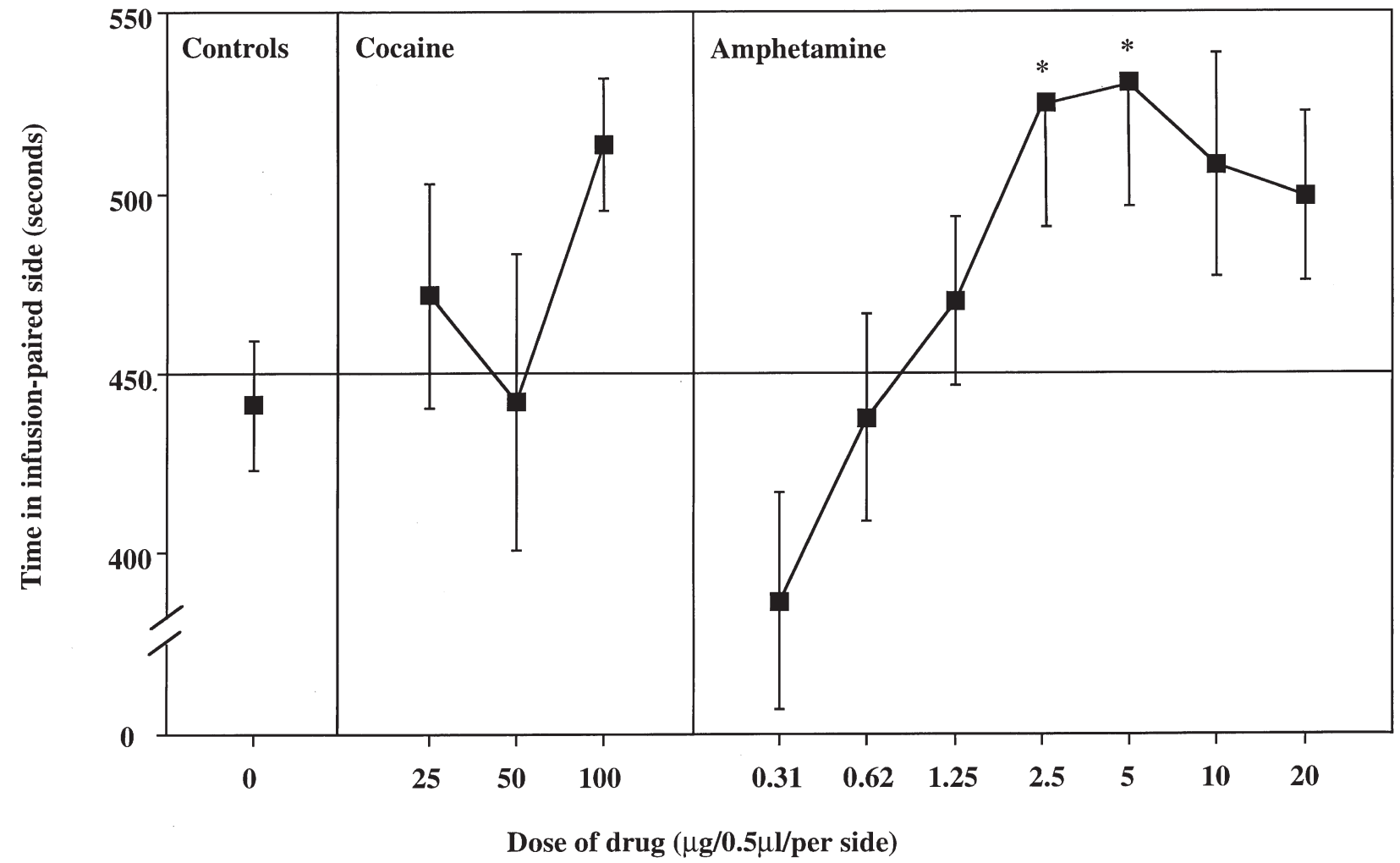

Figure 6. Time spent (sec $\pm S E M)$ in the infusion-paired compartment in rats that previously received intra-CeA infusion of saline, cocaine, or amphetamine. The horizontal line represents $50 \%$ of the total test time, such that values above the line reflect a preference for the infusion-paired compartment. Asterisks represent a significant increase in the amount of time spent in the infusion-paired side in conditioned rats relative to saline controls (Fisher LSD test, $p<.05$ ).

ing $10 \mu \mathrm{g} /$ side of amphetamine exhibited a trend toward spending more time in the infusion-paired compartment relative to saline controls ( $p<.06$, Fisher LSD test).

\section{DISCUSSION}

This study provides the first comparison of stimulant behaviors and CPP following ICV, intra-BlA, and intra$\mathrm{CeA}$ infusions of various doses of cocaine or amphetamine. As expected from previous research, ICV infusions of cocaine or amphetamine produced stimulant behaviors and CPP (Hemby et al. 1994; Morency and Beninger 1986; Calcagnetti and Schechter 1992). IntraBlA infusions of cocaine or amphetamine did not produce stimulant behaviors or CPP, with the exception of the highest dose of cocaine that produced an increase in locomotion. Intra-CeA infusions of the highest dose of cocaine also produced locomotion and a trend toward CPP. Intra-CeA infusions of amphetamine, however, potently produced rearing, locomotion, and CPP.

Support for a role of amygdaloid nuclei in initiating the behavioral effects of cocaine from the present study is tenuous because only the highest dose of cocaine (100 $\mu \mathrm{g})$ produced behavioral effects following infusions into these nuclei. A previous study indicated that behavioral effects produced by this high dose of cocaine are not likely region-specific due to diffusion to neighboring brain regions (Delfs et al. 1990). Thus, it is possible that the effects observed at the highest dose of cocaine in the present study may have been mediated by diffusion of drug to neighboring regions. It is also possible that the behavioral effects observed following intra-amygdala infusions of the highest dose of cocaine were due to local anesthetic effects in the amygdala. Consistent with this idea, intra-BlA infusions of tetrodotoxin, which inhibits spontaneous neuronal activity, increases the electrochemical signal in the NAc for the DA metabolite dihydroxyphenyl acedic acid (Louilot et al. 1985). Thus, the local anesthetic properties of the highest dose of cocaine may have inhibited neuronal activity in the BlA leading to an increase in DA neurotransmission in the NAc, thereby producing the increase in locomotion. The lack of region-specific and dose-dependent behavioral changes following intracranial infusions of cocaine in this study highlights the difficulties using intracranial administration of cocaine to localize behavioral effects of this drug.

In contrast to cocaine, the effects of amphetamine were dose-dependent and region-specific. Furthermore, 
the findings suggest that the CeA plays a role in initiating stimulant behavior produced by amphetamine. Specifically, intra-CeA infusions of low doses of amphetamine produced locomotion and rearing. In fact, intra-CeA infusions of amphetamine produced locomotion at a dose that was ineffective following ICV infusions. The dose-response curve for locomotion following intra-CeA infusions of amphetamine is consistent with previous research demonstrating that intra-CeA infusions of a high dose of amphetamine $(10 \mu \mathrm{g})$ do not alter stimulant behaviors, whereas infusions of a lower dose of amphetamine $(5 \mu \mathrm{g})$ produce an increase in locomotion and rearing irrespective of the amygdaloid nuclei (Carr and White 1987; Wang and Rebec 1996). The lack of locomotion at higher intra-CeA doses of amphetamine may be related to arousal processes, as stimulation of the CeA produces an arrest of ongoing behavior and an orienting response (see Kapp et al. 1992). Therefore, it is possible that these high doses produced an arrest of behavior that interfered with locomotion. Collectively, these findings suggest that the CeA plays a role in initiating stimulant behavior produced by amphetamine.

Intra-CeA infusions of amphetamine produced an inverted U-shaped dose-response curve for CPP. Specifically, intra-CeA infusions of low doses $(0-1.25 \mu \mathrm{g})$ or higher doses (10 and $20 \mu \mathrm{g}$ ) of amphetamine did not produce CPP, whereas intermediate doses $(2.5$ and 5 $\mu \mathrm{g})$ of amphetamine produced CPP. The finding that 10 $\mu \mathrm{g}$ infusions of intra-CeA amphetamine failed to produce CPP is consistent with a previous study by Carr and White (1986). The lack of CPP at higher doses of intra-CeA amphetamine is somewhat surprising given that ICV administration of these doses produced CPP. However, a meta-analysis of CPP effect size across doses of amphetamine administered systemically has revealed a similar inverted U-shaped change (Bardo et al. 1995). It is possible that high doses of amphetamine may be less rewarding or may produce aversive effects that compete with their rewarding effects.

The finding that the $\mathrm{CeA}$, but not the BlA, plays a role in initiating $\mathrm{CPP}$ produced by amphetamine is consistent with other studies that have examined reward. For example, electrical self-stimulation was elicited by electrodes placed into the CeA but not the BlA (Wurtz and Olds 1963). In addition, lesions of the CeA, but not the BlA, disrupted memory for the magnitude of reinforcement on an 8-arm radial maze (Kesner et al. 1989). Moreover, lesions of the CeA, but not the BlA, disrupt the ability of intra-NAc infusions of amphetamine to potentiate responding for a stimulus paired previously with a primary reinforcer. Based on these findings, Robledo et al. (1996) suggested that the BlA plays a role in forming associations between stimuli and rewarding effects, whereas the CeA plays a role in reward-related processes that are mediated by the NAc. The present study does not directly address the role of the CeA in reward-related processes that are mediated by the NAc. However, the finding that intra-CeA infusions of amphetamine produces locomotion and CPP, similar to intra-NAc infusions, suggests that the CeA and the NAc may share a common functional role in initiating motor behavior and reward produced by amphetamine (Carr and White 1986; Carr and White 1987). The notion that these structures share a common functional role is consistent with their anatomical relationship as part of the extended amygdala (Alheid et al. 1992). Therefore, the CeA may be part of a macrostructure in the brain that plays a role in initiating motor behavior and reward produced by amphetamine, and possibly cocaine.

The finding that psychomotor stimulant infusions into the BlA did not produce CPP suggests that BlA may not play a role in initiating reward. Conditioned reinforcement studies have demonstrated that this nucleus plays an important role in forming stimulus-reward associations (see Everitt and Robbins 1992; Hatfield et al. 1996). For example, lesions of the BlA, but not the $\mathrm{CeA}$, disrupt operant responding for a stimulus paired previously with a primary reinforcer (Hatfield et al. 1996; Robledo et al. 1996). Furthermore, previous research has demonstrated that lesions of the BlA altered the ability of cues to reinstate cocaine SA behavior but did not alter cocaine SA (Meil and See 1997). Therefore, it is likely that the BlA plays a role in forming associations between environmental stimuli and reward that is initiated elsewhere in the brain.

\section{ACKNOWLEDGMENTS}

The authors are grateful to Drs. Eddie Castañeda, Peter Killeen, and Stanley Parkinson for their comments on an earlier version of the manuscript. The authors also gratefully acknowledge the technical assistance of Dawn Charrier, Kathy Grote, Amanda Miller, and Brian Paul. This research was supported by the National Institute of Mental Health/Minority Neuroscience Training Program, the Howard Hughes Medical Institute through the Undergraduate Biological Science Education Program, and USPHS grant DA07730.

\section{REFERENCES}

Alheid GF, Heimer L (1988): New perspectives in basal forebrain organization of special relevance for neuropsychiatric disorders: the striatopallidal, amygdaloid, and corticopetal components of substantia innominata. Neurosci 27(1):1-39

Alheid GF, de Olmos JS, Beltramino CA (1992): Amygdala and extended amygdala. In Paxinos G (ed), The Rat Nervous System, 2nd Ed. New York, Academic Press, pp 495-572

Bardo MT, Rowlett JK, Harris MJ (1995): Conditioned place 
preference using opiate and stimulant drugs: A metaanalysis. Neurosci Biobehav Rev 19(1):39-51

Ben-Ari Y, Zigmond RE, Moore KE (1975): Regional distribution of tyrosine hydroxylase, norepinephrine and dopamine within the amygdaloid complex of the rat. Brain Res 87:96-101

Brown EE, Fibiger HC (1993): Differential effects of excitotoxic lesions of the amygdala on cocaine-induced conditioned locomotion and conditioned place preference. Psychopharmacol 113:123-130

Burns LH, Robbins TW, Everitt BJ (1993): Differential effects of excitotoxic lesions of the basolateral amygdala, ventral subiculum and medial prefrontal cortex on responding with conditioned reinforcement and locomotor activity potentiated by intra-accumbens infusions of d-amphetamine. Behav Brain Res 55:167-183

Cador M, Robbins TW, Everitt BJ (1989): Involvement of the amygdala in stimulus-reward associations: Interaction with the ventral striatum. Neurosci 30:77-86

Caine SB, Heinrich SC, Coffin VL, Koob GF (1995): Effects of the dopamine D-1 antagonist SCH-23390 microinjected into the accumbens, amygdala or striatum on cocaine self-administration in the rat. Brain Res 692:47-56

Calcagnetti DJ, Schechter MD (1992): Psychostimulantinduced activity is attenuated by two putative dopamine release inhibitors. Pharmacol Biochem Behav 43: 1023-1031

Carr GD, White NM (1986): Anatomical disassociation of amphetamine's rewarding and aversive effects: an intracranial microinjection study. Psychopharmacol 89: 340-346

Carr GD, White NM (1987): Effects of systemic and intracranial amphetamine injections on behavior in the open field: a detailed analysis. Psychopharmacol Biochem Behav 27:113-122

Delfs JM, Schreiber L, Kelley AE (1990): Microinjection of cocaine into the nucleus accumbens elicits locomotor activation in the rat. J Neurosci 10(1):303-310

Deminere JM, Taghzouti K, Tassin JP, LeMoal M, Simon H (1988): Increased sensitivity to amphetamine selfadministration after 6-OHDA lesions of the amygdala. Psychopharmacol 94:232-236

Everitt BJ, Robbins TW (1992): Amygdala-Ventral Striatal interactions and reward-related processes. In Aggleton JP (ed), The Amygdala: Neurobiological Aspects of Emotion, Memory, and Mental Dysfunction. New York, Wiley-Liss, pp 401-430

Everitt BJ, Cador M, Robbins TW (1989): Interactions between the amygdala and ventral striatum in stimulus-reward associations: Studies using a second-order schedule of sexual reinforcement. Neurosci 30(1):63-75

Fuller TA, Russchen FT, Price JL (1987): Sources of presumptive glutamatergic/aspartergic afferents to the rat ventral straitopallidal region. J Compar Neurol 258:317-338

Gerber GJ, Strech R (1975): Drug-induced reinstatement of extinguished self-administration behavior in monkeys. Pharmacol Biochem Behav 3:1055-1061

Hatfield T, Han JS, Conley M, Gallagher M, Holland P (1996): Neurotoxic lesions of the basolateral, but not central, amygdala interfere with Pavlovian second- order conditioning and reinforcer devaluation effects. J Neurosci 16(16):5256-5265

Hemby SE, Jones GH, Hubert GW, Neil DB, Justice JB (1994): Assessment of the relative contribution of peripheral and central components in cocaine place conditioning. Pharmacol Biochem Behav 47(4):973-979

Hiroi N, White NM (1991): The lateral nucleus of the amygdala mediates expression of the amphetamineproduced conditioned place preference. J Neurosci 11(7): 2107-2116

Kaada BR (1972): Stimulation and regional ablation of the amygdaloid complex with reference to functional representations. In Eleftheriou BE (ed), The Neurobiology of the Amygdala. New York, Plenum Press, pp 205-282

Kapp BS, Whalen PJ, Supple WF, Pascoe JP (1992): Amygdaloid contributions to conditioned arousal and sensory information processing. In Aggleton JP (ed), The Amygdala: Neurobiological Aspects of Emotion, Memory, and Mental Dysfunction. New York, Wiley-Liss, pp 229254

Kesner RP, Walser RD, Winzenried G (1989): Central but not basolateral amygdala mediates memory for positive affective experiences. Behav Brain Res 33:189-195

Kilts CD, Anderson CM (1987): Mesomaygdaloid dopamine neurons: differential rates of dopamine turnover in discrete amygdaloid nuclei of the rat brain. Brain Res 416:402-408

Koob GF, Robledo P, Markou A, Caine B (1993): The mesocorticolimbic circuit in drug dependence and reward-A role for the extended amygdala. In Kalivas PW, Barnes CD (eds), Limbic Motor Circuits and Neuropsychiatry. Boca Raton, CRC Press, pp 289-305

Louilot A, Simon H, Taghzouti K, Le Moal M (1985): Modulation of dopaminergic activity in the nucleus accumbens following facilitation or blockade of the dopaminergic transmission in the amygdala: a study by in vivo differential pulse voltammetry. Brain Res 346:141-145

McDonald AJ (1996): Glutamate and aspartate immunoreactive neurons of the rat basolateral amygdala: colocalization of excitatory amino acids and projections to the limbic circuit. J Comp Neurol 365:367-379

McGregor A, Baker G, Roberts DCS (1994): Effect of 6-hydroxydopamine lesions of the amygdala on intravenous cocaine self-administration under a progressive ratio schedule of reinforcement. Brain Res 646:273-278

McGregor A, Roberts DCS (1993): Dopaminergic antagonism within the nucleus accumbens or the amygdala produces differential effects on intravenous cocaine self-administration under fixed and progressive ratio schedules of reinforcement. Brain Res 624:245-252

Meil WM, See RE (1997): Lesions of the basolateral amygdala abolish the ability of drug associated cues to reinstate responding during withdrawal from self-administered cocaine. Behav Brain Res 87(2):139-148

Morency MA, Beninger RJ (1986): Dopaminergic substrates of cocaine-induced place conditioning. Brain Res 399: 33-41

O’Dell LE, Khroyan TV, Neisewander JL (1996): Dosedependent characterization of the rewarding and stimulant properties of cocaine following intraperitoneal and intravenous administration in rats. Psychopharmacol 123:144-153 
Post RM, Weiss SRB, Pert A (1987): The role of context and conditioning in behavioral sensitization to cocaine. Psychopharmacol Bull 23(3):425-429

Paxinos G, Watson C (1986): The Rat Brain in Stereotaxic Coordinates. New York, Academic Press

Robledo P, Robbins TW, Everitt BJ (1996): Effects of excitotoxic lesions of the central amygdaloid nucleus on the potentiation of reward-related stimuli by intra-accumbens amphetamine. Behav Neurosci 110:981-990

Stewart J (1992): Conditioned stimulus control of the expression of sensitization of the behavioral activating effects of opiate and stimulant drugs. In Gormezano I, Wasserman EA (eds), Learning and Memory: The behavioral and biological substrates. New Jersey, Erlbaum, pp 129-151

Ungerstedt U (1971): Stereotaxic mapping of the monoamine pathways in the rat brain. Acta Physiol Scan Suppl 367:1-48

Wallace DM, Magnuson DJ, Gray TS (1992): Organization of amygdaloid projections to dopaminergic, noradrenergic, adrenergic cell groups in the rat. Brain Res Bull 28:447-454

Wang Z, Rebec GV (1996): Amygdaloid neurons respond to clozapine rather than haloperidol in behaving rats pretreated with intra-amygdala amphetamine. Brain Res 711:64-72

Whitelaw RB, Markou A, Robbins TW, Everitt BJ (1996): Excitotoxic lesions of the basolateral amygdala impair the acquisition of cocaine-seeking behavior under a second-order schedule of reinforcement. Psychopharmacol 127:213-224

Wurtz RH, Olds J (1963): Amygdaloid stimulation and operant reinforcement in the rat. J Comp Physiol Psychol 56(6):941-949 